\title{
El método biográfico-narrativo. Una herramienta para la investigación educativa
}

\author{
MA. DEL ROSARIO LANDÍN MIRANDA* \\ SANDRA IVONNE SÁNCHEZ TREJO ** \\ Universidad Veracruzana - México \\ Recibido el 10-07-2017; primera evaluación el 20-11-2018; \\ segunda evaluación el 18-02-2019; aceptado el 27-02-2019
}

\section{RESUMEN}

Uno de los métodos que nos ha permitido explorar de manera diferente nuestro conocimiento sobre la práctica docente y la educación en general ha sido el biográfico-narrativo. Consideramos que el método biográfico-narrativo nos lleva a captar ese conocimiento genuino que un sujeto construye desde su experiencia vivida en diversos espacios y tiempos, permitiéndonos comprender la verdadera esencia de la educación. En este trabajo, integramos una síntesis como parte de nuestra experiencia de investigación con dicho método, abordando sus aportaciones en el campo de la educación, los obstáculos para su desarrollo y su reconocimiento como una forma diferente de generar conocimiento.

Palabras clave: investigación educativa, narrativa, experiencia educativa, conocimiento.

\footnotetext{
Doctora en Pedagogía por la Universidad de Barcelona, España. Profesora de Tiempo Completo y Coordinadora del Área de Investigación Educativa de la Facultad de Pedagogía, Universidad Veracruzana Campus Poza Rica-Tuxpan. Miembro del Sistema Nacional de Investigadores del Consejo Nacional de Ciencia y Tecnología (CONACyT). Miembro del Consejo Mexicano de Investigación Educativa (COMIE) y del Colegio de Pedagogos de México. Es colaboradora del Cuerpo Académico: Educación, Cultura y Sociedad con registro ante el Programa de Desarrollo Profesional Docente (PRODEP) de la Secretaría de Educación Pública. Ha participado como ponente en congresos nacionales e internacionales. Correo: rlandin@uv.mx, rlandin17@gmail.com

** Maestra en Gestión del Aprendizaje por la Facultad de Pedagogía, Universidad Veracruzana. El programa de Maestría cuenta con el registro del Programa Nacional de Posgrados de Calidad del Consejo Nacional de Ciencia y Tecnología (CONACYT). Fue becada para realizar estudios de posgrado por dicho Consejo, obteniendo reconocimiento por su trayectoria académica. Fue becada como ayudante adjunta para realizar investigación por la Dirección General de Investigaciones de la Universidad Veracruzana. Se desempeńa como profesora en la Escuela Secundaria Art. 3ero. en la Ciudad de Poza Rica, Ver. Ha participado como ponente en congresos nacionales e internacionales. Correo: chenix28lp@gmail.com
} 


\section{The biographical-narrative method. A tool for educational research}

\section{Abstract}

One of the methods that has allowed us to explore in a different way our knowledge about teaching practice and education in general has been the biographical-narrative. We consider that the biographical-narrative method leads us to capture that genuine knowledge that a subject constructs from his experience lived in different spaces and times, allowing us to understand the true essence of education. In this work we integrate part our research experience with this method, addressing its contributions in the field of education, the obstacles to its development and its recognition as a different way of generating knowledge.

Keywords: educational research, narrative, educational experience, knowledge.

\section{O método biografia-narrativa. Uma ferramenta para a investigaçáo educativa Resumo}

Um dos métodos que nos tem permitido explorar de maneira diferente o nosso conhecimento sobre a prática docente e a educação em geral tem sido o biografianarrativa. Consideramos que o método biografia-narrativa nos leva a captar esse conhecimento genuíno que um sujeito constrói desde a sua experiência vivida em diversos espaços e tempos, permitindo-nos compreender a verdadeira essência da educação. Neste trabalho integramos uma síntese como parte da nossa experiência da investigaçáa com esse método, abordando suas contribuiçôes no campo da educação, os obstáculos para o seu desenvolvimento como uma forma diferente de gerar conhecimento.

Palavras-chave: investigação educativa, narrativa, experiência educativa e conhecimento. 


\section{INTRODUCCIÓN}

Con el auge de los estudios cualitativos en el campo de la educación, se abre una nueva perspectiva de investigación donde se reconoce al sujeto como un actor activo que posee un rico conocimiento construido por su interacción en diversos contextos y tiempos. Es, con el método biográfico narrativo, el cual se ubica dentro del campo de la investigación cualitativa, que podemos dar cuenta de ese rico conocimiento, pues se trabaja con los sujetos a través de la narración que viaja por la memoria para sacar a la luz aquellas experiencias, aquellas imágenes, aquellos recuerdos, sentimientos, ideales, aprendizajes y significados contextualizados en determinado tiempo y espacio. En este sentido, el ejercicio narrativo nos permite: generar estados de reflexión y de conciencia sobre las experiencias vividas, generar una práctica para el establecimiento del diálogo que nos lleva a la develación de subjetividades en conjunto e identificar aquellos genuinos procesos educativos desde donde se ha aprendido y construido el conocimiento.

Narrar es relatar, contar, informar acerca de algo, algo que lleva un sentido, tanto para quien lo narra como para quien lo escucha o lo lee. Narrar es un proceso que activa la reflexión para dar sentido a la experiencia vivida y develar los significados construidos generados por la relación que las personas establecen con su mundo. He aquí el papel de la narrativa en la investigación educativa, la cual, como mencionan Contreras y Pérez (2010), no está centrada en dar cuenta de una realidad, en explicarla, sino en preguntarse por el sentido educativo que puede abrirse a una experiencia que tratamos de entender.

El método biográfico-narrativo tiene grandes aportaciones en el campo educativo, como más adelante lo abordaremos, pues va más allá de explicaciones causales, de reducir la realidad a variables medibles. Es un método que nos brinda la oportunidad de ir a la verdadera esencia de la educación: las complejas interacciones que las personas hacen día a día, en tiempo y espacio, configurando su identidad individual y social, construyendo y reconstruyendo historias personales y sociales (Connelly y Clandinin, 1995).

Fruto de nuestra experiencia en el desarrollo de investigaciones con el método biográfico-narrativo ${ }^{1}$, fue que integramos el presente trabajo, donde

\footnotetext{
1 En el contexto de la Universidad Veracruzana, Región Poza Rica-Tuxpan, hemos tenido la experiencia de realizar algunos estudios usando el método biográfico-narrativo con profesores jubilados (2015-2017), con profesores-investigadores adscritos al Sistema Nacional de Investigadores (SNI) del Consejo Nacional de Ciencia y Tecnología (CONACyT) (2016). Ambos estudios financiados por el Programa de Desarrollo del Profesorado (PRODEP) de la Secretaría de Educación Pública. Así también, se realizó un proyecto de intervención educativa con profesoras de la Escuela Secundaria Art.
} 
mencionamos algunos aspectos importantes que se deben tomar en cuenta cuando se pretende realizar una investigación con este método, abordamos su ubicación en la investigación cualitativa, algunos aspectos centrales del método biográfico-narrativo, sus aportaciones en el campo de la educación, consideraciones éticas, los obstáculos para su desarrollo y conclusiones.

\section{LA INVESTIGACIÓN BIOGRÁFICO-NARRATIVA}

La investigación biográfica narrativa tiene sus orígenes en la Escuela de Chicago, principalmente con la interesante obra de Thomas y Znaniecki «El campesino polaco en Europa y América», publicada entre los ańos 1918 y 1920 (Camas, 2001). Autores como Pujadas (1992) reconocen que, en esta obra, «se empezó a usar el término life history para describir tanto la narrativa vital de una persona recogida por un investigador, como la versión final elaborada a partir de dicha narrativa, más el conjunto de registros documentales y entrevistas a personas del entorno social del sujeto biografiado, que permiten completar y validar el texto biográfico inicial» (p. 13).

No es nuestro propósito ahondar sobre la Escuela de Chicago, pero sí es necesario mencionar que ha sido un referente obligado para conocer los orígenes de la investigación cualitativa y los estudios narrativos (Goodson, 2004). En este sentido, Mallimaci y Giménez (2009) afirman que la Escuela de Chicago ha sido precursora e innovadora en los estudios biográficos, donde «las historias de vida, lo biográfico y el estudio de casos forman parte de otra manera de hacer sociología desde principios del siglo XX, y muestran también las múltiples experiencias e interrogantes que surgen de las nuevas prácticas de investigación» (p. 179).

La Escuela de Chicago llamada así, por el conjunto de investigadores, profesores y estudiantes dedicados los estudios de la vida social urbana asociados al Departamento de Sociología de la Universidad de Chicago, se funda en 1892, sin embargo, fue con las aportaciones ideológicas de William Thomas, Robert Park y Ernest Burgess que esta Escuela tiene un período de gran aportación a la investigación social. Así también se reconoce la gran influencia del pragmatismo de John Dewey y el interaccionismo simbólico de George H. Mead y de Herbert Blumer.

Durante 1910 y 1940, en la Escuela de Chicago se divulgaron interesantes estudios basados en los métodos cualitativos, usando historia de vida, observación 
participante y documentos personales, para estudiar la situación social que en esos años se vivía en la ciudad de Chicago: la migración, problemas de violencia y otras situaciones sociales. Entre los estudios realizados podemos encontrar a: Anderson, The Hobo, 1923; Cressey, The Taxi-Dance Hall, 1932; Thrasher, The Gang, 1927; Wirth, The Ghetto, 1928; Zorbaugh, The Gold Coast and the Slum, 1929, dan cuenta de estudios detallados de observación participante sobre la vida urbana. Por otro lado, existieron estudios sobre historias de vida de criminales y delincuentes juveniles, por ejemplo: Shaw, The Natural History of a Delinquent Career, 1931; Shaw, The Jack Roller, 1930; Shaw y otros, Brothers in Crime, 1938; Sutherland, The Professional Thief, 1937 y un estudio clásico sobre la vida de los inmigrantes y sus familias en Polonia y los Estados Unidos de Norteamérica basado en documentos personales de Thomas y Znaniecki, The Polish Peasant in Europe and America, 1918-1920 (Azpúrua, 2005; Flick, 2004; Pujadas, 1992; Taylor y Bogdan, 1987); entre otros estudios más.

A pesar de estos interesantes estudios, la metodología cualitativa tuvo un decline comprendido a final de la década de 1940 y principios de la de 1950, debido al creciente uso de los métodos cuantitativos. Sin embargo, el paradigma cualitativo-interpretativo resurge en la década de 1960 con una diversidad de sólidos estudios basados en los métodos cualitativos que permiten dar impulso a un movimiento con identidad en aspectos epistemológicos, metodológicos y ontológicos, superando la rigidez de la investigación positivista y dando grandes aportaciones a la investigación educativa.

Por otro lado, de acuerdo con Bolívar (2002; 2014), la investigación biográfica y narrativa en educación se ubica en esa revolución hermenéutica que se da durante la década de 1970 en las ciencias sociales, donde el significado de los actores se convierte en el foco central de la investigación, así como la propia experiencia y la construcción social de la realidad.

En este sentido, Bolívar y Segovia (2006) mencionan que «la investigación biográfico-narrativa, permite que afloren y se desarrollen perfiles que vinculen las estrategias cualitativas de investigación de los actores reales de la vida cotidiana. En este caso la narración biográfica ofrece un marco conceptual y metodológico para analizar aspectos esenciales del desarrollo humano y establece sus líneas personales y expectativas de desarrollo» (Huchim y Reyes, 2013, p. 16).

La narrativa es una estrategia de investigación que permite plantear una forma diferente de construir conocimiento, ya que de acuerdo con Connelly y Clandinin (1995), «la narrativa está situada en una matriz de investigación cualitativa puesto que está basada en la experiencia vivida y en las cualidades de la vida y de la educación» (p. 16). Los mismos autores mencionan que 
«la razón principal para el uso de la narrativa en la investigación educativa es que los seres humanos somos organismos contadores de historias, organismos que, individual y socialmente, vivimos vidas relatadas. El estudio de la narrativa, por lo tanto, es el estudio de la forma en que los seres humanos experimentamos al mundo» (Connelly y Clandinin 1995, p. 11).

Es la narración de la experiencia vivida la que nos lleva a conocer los contextos y los tiempos en los que tuvo sentido. Retomando a Bruner (1999), la construcción narrativa de la realidad se caracteriza por poseer una estructura de tiempo cometido que considera la segmentación del tiempo como acontecimientos a los cuales les otorgamos sentidos y significados.

Desde esta perspectiva, el sujeto es reconocido como un agente activo, donde la subjetividad cobra un papel fundamental a diferencia del paradigma cuantitativo. Morińa (2017) afirma que, con la investigación narrativa, «surge una crisis de los modos paradigmáticos establecidos de conocer, donde se replantea el papel del investigador y la necesidad de incluir la subjetividad para comprender la realidad de las personas que narran sus historias» (p. 19). En este sentido, reconocer la subjetividad en la investigación narrativa significa abrirse al conocimiento del otro, a conocer su experiencia, historia y aprendizaje. Es dar la oportunidad a que los sujetos hablen desde ellos mismos dándoles voz y presencia. Hacer investigación en el campo de la narrativa es atender a una forma diferente de construir conocimiento, puesto que quien investiga llega a ser meramente la conexión entre el campo, la investigación y la comunidad para asegurar que esas voces sean oídas (Moriña, 2017).

Develar el campo de la subjetividad es una acción que nos lleva a reconocer al sujeto como ser histórico y social, que es y está siendo en relación con su mundo, ello implica abrir:

El espacio para una recuperación del pensamiento en su función tanto constructora de conocimiento como de reflexión acerca de la condición humana. Se muestra el auto-desafío del sujeto, en su necesidad de ser, tanto en su soledad como en su misterio. Pues pudiendo la soledad ser nuestro misterio, la conciencia que desarrollamos de ella es nuestra verdad, la cual deviene en humanidad cuando convertimos en posibilidad de encuentro con otros (Zemelman, 2002, p. 14).

Con esta reflexión, la historicidad del sujeto queda al descubierto, su relación ser-estando con su mundo, su forma de establecer la relación con su mundo y con los otros, en cualquiera de los espacios de despliegue posibles, su forma de construir experiencias generadoras de aprendizajes, de sentimientos y de vivencias diversas. 


\subsection{El método biográfico-narrativo: aspectos centrales}

Trabajar con el método biográfico-narrativo nos ha llevado a reconocer algunos aspectos centrales que son necesarios abordar. Este método se focaliza en la experiencia de los sujetos. La experiencia, en esencia, es narrativa. Su relato permite viajar por los pasajes de la memoria en tiempo y espacio. Para Ricoeur (2013a) «es el relato, la trama narrativa, el medio privilegiado para esclarecer la experiencia temporal inherente a la ontología del ser-en-el-mundo» (pp. 25-26). La narrativa, la experiencia y el tiempo están estrechamente relacionados pues dan cuenta del sujeto, de su existencia y su interacción con su mundo.

La narrativa despliega y clarifica la experiencia temporal, llevándonos a su propia develación para identificar ese hilo conductor de sentidos y ese entretejido de significados, encontrando esa relación dialéctica entre experiencia y aprendizaje: la experiencia de aprender y aprender desde la experiencia, tanto individual como compartida. Una relación dialéctica que además es multifacética, relacional y compleja (Boud, Cohen y Walker, 2011).

Por otro lado, el saber de la experiencia tiene un claro contenido narrativo: transcurre en el tiempo, refleja las vivencias e implicaciones subjetivas de sus protagonistas. En este sentido, vemos claramente cómo las formas narrativas del saber educativo buscan dilucidar las cualidades pedagógicas de la experiencia mientras se mantiene el sentido integral de la misma, pues «investigar la experiencia no es transformarla en otra cosa, sino acompañarla, interrogarla, desvelando significados y sentidos potenciales» (Contreras y Pérez, 2010, p. 45).

Otro aspecto a considerar es la memoria. Si bien la narrativa lleva a poner claramente el lugar de la memoria, en la cual se encuentran entretejidos imágenes, recuerdos, pasajes y escenarios. El ejercicio narrativo de la memoria lleva al sujeto a una rememorización y memorización Ricouer (2013b), donde se juega con la conciencia de un acontecimiento reconocido en el tiempo y el aprendizaje sobre lo que pudo desarrollarse desde tal acontecimiento; donde el olvido y el tiempo también se juegan para la reconstrucción de la memoria. Estamos ante el plano fenomenológico de la memoria.

Nuestra experiencia en este tipo de investigación y la literatura existente sobre esta temática, nos llevan a reconocer la importancia que tiene manejar diversas estrategias y documentos, a saber: historia de vida, la entrevista biográfica, narrativa o en profundidad, diarios, historias y relatos de familia, las fotografías, las memorias, documentos personales, escritos autobiográficos, las cartas, notas de campo, entre otras más (Moriña, 2017; Bolivar, 2014; 
Pons y Hernández, 2013; Mallimaci y Giménez, 2009; Connelly y Clandinin, 1995).

Desde esta perspectiva, se visualiza una epistemología diferente tanto para la investigación como para la educación y la pedagogía, promover procesos de formación desde y para el otro; es decir, implica trabajar desde el ser y desde su subjetividad, pues el ser tiene un lugar y un tiempo, así como un escenario y una temporalidad que implican una relación en y para el otro. De acuerdo con Contreras y Pérez (2010), la apertura al encuentro del otro, a su comprensión, ocurre en el seno de la relación, en el intento de reconocimiento y aceptación, así como de desencuentro y conflicto o de insondable misterio. Es así como el considerar a la narrativa como una forma de investigación (Larrosa, et al. 1995) implica abrirse a la posibilidad de vivir experiencias que llevan a una continua relación con el otro u otros, identificando y develando subjetividades en conjunto.

Nos situamos ante una forma diferente de ver a la realidad, al hombre. Retomamos las aportaciones de María Zambrano cuando describe al hombre como un gran creador, pero encubierto, envuelto ante los velos del olvido. Para Zambrano (2006), "el hombre es una criatura afortunada y su única desgracia consiste en tener que esperar y en la espera desvelarse, desvelar lo que le está encubierto, pero ¡tan propicio de ser desvelado!» (p. 30). En este sentido, Zambrano plantea una nueva forma de concebir el conocimiento escapando de la rigidez de la ciencia. El conocer, para esta autora, es «acordarse, y acordarse es reconocerse en lo que es, desvanecer el velo del olvido, la sombra, para en la luz, ser íntegramente. Porque el hombre, es, y sólo tiene que reconocerlo» (p. 31).

Estos elementos centrales del método biográfico-narrativo nos llevan a identificar las cuestiones epistemológicas, ontológicas y metodológicas en su operatividad, sin perder de vista que el método biográfico-narrativo se preocupa "por dar cuenta del sentido que para el actor tiene la realidad social que vive, las acciones propias y de otros actores, más que cuantificar o medir la realidad social» (Reséndiz, 2015, p. 127).

En el contexto de la Universidad Veracruzana y en México en general, aún se sigue promoviendo una formación en investigación y estudios desde el paradigma cuantitativo. Son pocos los esfuerzos por hacer investigación cualitativa y, más aún, desde el método biográfico-narrativo. Por ello, surge nuestro interés de compartir la riqueza de este método y sus bondades en el campo de la educación. 


\section{Aportaciones EN El CAMPO DE La EDUCACión}

Aunque ya hemos mencionado, en los apartados anteriores, algunos aspectos del método biográfico-narrativo relacionados con el campo de la educación, queremos hacer un puntual énfasis al respecto.

La narrativa en el campo de la educación se convierte en una excelente estrategia mediante la cual los profesores pueden documentar su práctica para compartir con otros colegas aquellas estrategias que les han sido más o menos exitosas, con el propósito de aprender de los demás y aprender de sí mismos.

El ejercicio de documentar la práctica lleva a desarrollar potenciales docentes y aportar conocimientos en los contextos institucionales, pero lo más enriquecedor es la generación de la reflexión y autorreflexión desde la práctica y para la práctica, reconociendo fortalezas y debilidades, enriqueciendo las acciones y proponiendo otras nuevas. Por otro lado, también se pueden integrar documentales sobre historias de vida, conversaciones, perfiles, retratos, anecdotarios, entre otras estrategias más, que se convierten en experiencias exitosas de los profesores, como ejemplo en la formación de los estudiantes. Es así como todo registro, en el campo de la narrativa-biográfica, lleva a una búsqueda de trascendencia en el tiempo y ha hecho de la vida - y consecuentemente, de la "propia» experiencia - un núcleo esencial de tematización (Arfuch, 2007) y de investigación.

La narrativa lleva al sujeto a descubrir su propia interioridad en un ejercicio de autorreflexión y autoobservación; favorece el refuerzo de la memoria, trayendo a colación el recuerdo en contextos situados y temporales. Es un ejercicio que va y viene para estimular nuestra propia capacidad de recordar las cosas, superando el pragmatismo y la inmediatez en nuestra forma de vivir, de ser y estar en tiempo y espacio.

Por otro lado, la narración de la experiencia, de acuerdo con Fernández (2012), está caracterizada por al menos cuatro elementos básicos que permiten la reflexión y análisis de la práctica educativa y formativa:

a) La inclusión de la perspectiva temporal. La elaboración de un relato de la experiencia ofrece la oportunidad al profesor de reconstruir de manera narrativa su experiencia pasada, de contrastarla con la situación actual y de anticipar la evolución futura.

b) La integración de las diversas dimensiones del desarrollo del profesor. La narración de la experiencia se nutre de referencias al propio desarrollo que ofrecen una perspectiva global del aprendizaje de la profesión y de su evolución sin caer en la separación artificiosa entre lo "personal» o privado y lo "profesional» o público. 
c) La superposición de los distintos planos de referencia del desarrollo curricular. Los relatos se enmarcan en un escenario común donde se superponen los distintos marcos organizativos o planos de referencia de los diversos niveles de desarrollo del currículum -aula, ciclo/departamento, centro.

d) La simultaneidad de enfoques. La espontaneidad del hilo narrativo provoca un constante cambio de enfoque desde la globalidad al detalle y, de nuevo, a la globalidad, que lejos de ofrecer imágenes fragmentadas superpuestas permite hacer una lectura simultánea del enfoque ejemplificador del detalle y del enfoque justificativo de la referencia global (p. 25).

El trabajo narrativo es de acompañamiento con el otro, lo que favorece la comprensión de la realidad educativa en un proceso dialógico, social e intersubjetivo. Además, aporta nuevas líneas de investigación que dan pie a la creatividad y originalidad en el desarrollo de la misma, así como también favorece estudios sobre el desarrollo profesional del profesorado.

El uso del método biográfico-narrativo, en el campo educativo, nos lleva a considerar que la educación es experiencia y la experiencia es experiencia educativa. Tal consideración permite reconocer un proceso de reflexión y aprendizaje para crearnos a nosotros mismos lo que requiere experimentar las cualidades del entorno, cualidades que alimentan nuestra vida conceptual y que luego usamos para alimentar nuestra imaginación, a expandirla hacia lo posible, desde la reflexión de lo vivido, desde lo acontecido, donde, en palabras de Green (2005) «se abre la posibilidad de formular modos alternativos de vivir, valorar y elegir» (p. 44).

El método biográfico-narrativo permite clarificar y comprender el sentido de lo vivido, pues, según Dewey (1934), citado en Green (2005), la comprensión «es lo que convierte la experiencia en lúcida y consciente de sí misma. Sin esa comprensión, «solo existe la repetición, la uniformidad completa; la experiencia resultante es rutinaria y mecánica». La conciencia siempre tiene una fase imaginativa, y la imaginación, más que ninguna otra capacidad, rompe con la inercia del hábito» (p. 41). La imaginación, según Elliot (2004), «nos ofrece imágenes de lo posible que constituyen una plataforma para ver lo real, y al ver lo real con ojos nuevos, podemos crear algo que se encuentra más allá de ello» (p. 20); además, Green (2005) nos indica que la imaginación brinda «nuevos cristales con los que mirar hacia fuera e interpretar lo actos educativos que mantienen vivos a los seres humanos y sus culturas» (p. 37).

En estos tiempos de modernidad, de tecnología en todos los ámbitos de nuestra vida, nos hace falta imaginar, crear, aventurarnos a nuevas experiencias de aprendizaje, ir a la esencia de nuestro ser, para mirar con amplia visión nuestro mundo, nuestra relación con el otro, para nombrar con nuevas palabras el acto de educar y de formar. 


\section{Consideraciones Éticas}

El método biográfico-narrativo nos lleva a adentrarnos a diversos tiempos, realidades y experiencias para rescatar el conocimiento que hay allí de manera escrita. La tarea del investigador es captar e interpretar lo que está plasmado en los documentos personales, fotografías, notas, diarios, cartas, etc., y entretejerlo con las narraciones que los sujetos dan. Pero, en esta gran tarea, el investigador no debe perder de vista la ética en el manejo tanto de los documentos como de la información que va obteniendo.

Al respecto, Fernández (2012) considera fundamental cuidar tres principios éticos en la investigación biográfica-narrativa:

1. Principio de respeto a la autonomía personal. Se debe de tener el consentimiento explícito para ser sujeto de la investigación; cuidar que el investigado no se sienta estafado o engañado con respecto a los objetivos establecidos y la información que ha proporcionado la cual debe validarla previo y posterior al análisis.

2. Principio de confidencialidad. Es brindar al sujeto investigado garantía de anonimato.

3. Principio de justicia. Es imprescindible no juzgar las o sancionar las ideas, experiencias y formas de pensar de los sujetos de estudio. Es por ello que la escucha atenta libre de prejuicios debe de estar presente en todo momento de la investigación (p. 23).

Además de estos principios, es fundamental cuidar la validez de la investigación: tal como lo sugieren Taylor y Bodgan (1987), un investigador debe asegurar la pertinencia y relación entre los datos y lo que las personas dicen y hacen. Esto implica un ejercicio cuidadoso y atento durante el análisis de la información, implica estados de reflexividad y una habilidad de interpretación para captar el sentido y el significado de dicha información.

El método biográfico-narrativo es apasionante en su desarrollo, pero requiere de no perder claridad en sus objetivos, en los tiempos y espacios, en la forma de interactuar con los sujetos de la investigación. Exige una sólida formación de quien pretende llevarlo a cabo para no caer en la simplicidad de contar historias y en la falsedad de hacer entrevistas y recolectar documentos.

La investigación biográfico-narrativa se basa en diversas fuentes de datos narrativos, como anteriormente se ha mencionado, así como en la diversidad de las formas en que se pueden presentar dichos datos, que dan cuenta del mundo empírico producido por el sujeto. En este sentido, la tarea del investigador es la de interpretar la vida de un sujeto en un continuo contexto experiencial, dar cuenta de los tiempos y los momentos en que un sujeto vivió 
y ha vivido sus experiencias. Es así como el tiempo y el espacio, la trama y el escenario trabajan juntos para crear la cualidad experiencial de la narrativa (Connelly y Clandinin, 1995) y su temporalidad (Ricoeur, 2013b).

Por otro lado, Sanmartín (2003) menciona que «la investigación biográfica es esencialmente una descripción fenomenológica que exige de cuatro habilidades procedimentales en el investigador: observar, escuchar, comparar y escribir para la práctica de la investigación cualitativa» (citado en Sanz, 2005, p. 104). Al respecto, Mills (1959) menciona que «esas cuatro habilidades, que hay que poner en juego, se concretan en una serie de etapas, que exigen a la par sistematicidad y cierta dosis de artesanía» (citado en Sanz, 2005, p. 104). Construir y dar forma a la narrativa es todo un arte. El interés, el ingenio, la perspicacia y la creatividad son elementos fundamentales para un investigador narrativo.

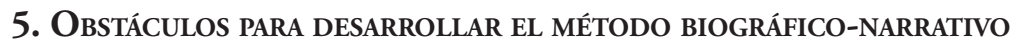

El desarrollo del método biográfico-narrativo no ha sido fácil, ya que hemos encontrado algunos obstáculos que consideramos importantes mencionar.

Por nuestra interacción con diversos profesores, hemos podido observar que ellos mismos no valoran sus experiencias y aprendizajes como una fuente de conocimiento para ser compartida con otros colegas. Esto debido a la ausencia de espacios que les llevasen a reflexionar desde sus propias experiencias. Nunca se tuvo ni se dio la oportunidad de documentar sus prácticas docentes, sus vivencias y experiencias dentro y fuera del aula, todo ello quedándose en el tiempo, en la memoria y, a veces, atrapadas en el olvido. Esta situación ha sido originada precisamente por el peso de la filosofía positivista en los diseños curriculares y la rigidez institucional que enmarcó el desarrollo de su práctica docente y ocultó el valor de sus experiencias y vivencias.

Dado que el método biográfico-narrativo no es muy conocido, se tiene desconfianza por parte de los sujetos para compartir la información sobre su vida, sus experiencias y sus documentos personales.

La narrativa como método nos permite reproducir las experiencias de vida, pero también puede reproducir la falsedad en los datos. Tal como lo afirman Connelly y Clandinin (1995), «no solo se pueden «falsificar los datos» y escribir una ficción, sino que también se pueden utilizar los datos para contar una mentira tan fácilmente como pueden utilizarse para contar una verdad» (p. 44). Al respecto, un investigador biográfico siempre se enfrentará a historias y biografías que constituyen solo un recorte de la realidad de un sujeto, pues la memoria es selectiva y, en ocasiones, llena de confusiones y olvidos. 
Por otro lado, se sigue cuestionando la confiabilidad y credibilidad de la información que se obtiene del método biográfico-narrativo por trabajar, tanto con la subjetividad de los sujetos, como con la propia subjetividad del investigador.

En México y en particular en la Universidad Veracruzana, existe un peso aún muy fuerte por la investigación experimental, tanto en los centros de investigación como en la Universidad y en los organismos para el financiamiento de proyectos de investigación. Desde nuestra experiencia, observamos que son pocos los esfuerzos por impulsar la investigación cualitativa y las metodologías biográfico-narrativas.

\section{Conclusiones}

Hasta aquí, presentamos nuestros argumentos desde la experiencia de investigación que hemos tenido con el método biográfico-narrativo, la interacción con profesores universitarios y de educación secundaria. No pretendemos apologizar el conocimiento que desde este método podemos obtener, pero sí reconocemos, desde nuestra experiencia y la literatura existente, que nos brinda la oportunidad de construir un conocimiento de manera diferente, basado en el diálogo y la participación en conjunto. Así también, nos brinda la oportunidad de adentramos a cuestiones no reconocidas por la investigación cuantitativa: la experiencia vivida, la subjetividad de los individuos, su memoria, recuerdos, emociones, el tiempo y los significados construidos. Estos aspectos, entre otros más, despertaron nuestra curiosidad por conocer a mayor detalle el método biográfico-narrativo, nos llevó a una búsqueda de aquellos colegas que nos compartieran su propia experiencia en el desarrollo de dicho método. Del mismo modo, nos llevó a la búsqueda de diversos espacios académicos donde exponer nuestro propio conocimiento y nuestras ignorancias, nuestras interrogantes y forma de pensar, mirar e investigar con el método biográfico-narrativo.

Concretamente, este método nos ha brindado la oportunidad de contar con espacios para reconstruir una parte de la historia de la propia Universidad Veracruzana, México, donde la reflexión en conjunto se hace presente, donde la memoria se activa para rescatar aquello que se había quedado en el olvido. Por otro lado, nos ha permitido conocer las características, las experiencias vividas y los contextos de diversos profesores: sus actividades diarias, lo cotidiano de su vida escolar y los significados construidos, llevándoles a la reflexión desde y para la práctica educativa con el propósito de mejorarla.

Esperamos que este trabajo sea inspirador para enriquecer la mirada e impulsar estudios tanto cualitativos como con el método biográfico-narrativo, 
tan necesarios en el campo de la educación dada la extrema racionalidad técnica y burocracia institucional. Los espacios áulicos necesitan ser mirados con creatividad e imaginación; por ello, queremos cerrar nuestro escrito con una cita de Contreras y Pérez (2010):

La necesidad de nuevas palabras en educación es urgente, si queremos pensar más allá de lo institucionalizado y de lo ya asentado en nuestro pensamiento, en nuestra imaginación, en nuestra capacidad perceptiva, si queremos alumbrar nuevas prácticas, o si queremos darle presencia, visibilidad a aquellas dimensiones de lo educativo que, con ser las más sutiles, de las que no suele hablarse, son a la vez fundamentales, las primeras, las que sostienen la trama de lo educativo (p. 82).

\section{REFERENCIAS BIBLIOGRÁFICAS}

Arfuch, L. (2007). Elespacio biográfico. Dilemas de la subjetividad contemporánea. México: Fondo de Cultura Económica.

Azpúrua, F. (2005). La Escuela de Chicago. Sus aportes para la investigación en ciencias sociales. Sapiens. Revista Universitaria de Investigación, 6(2), 25-35. Recuperado de https://www.redalyc.org/ pdf/410/41021705003.pdf

Bolivar, A. (2002). «¿De nobis ipsis silemus?»: Epistemología de la investigación biográfica-narrativa en educación. Revista Electrónica de Investigación Educativa, 4(1). Recuperado de http://redie.uabc.mx/ redie/article/view/49/91

Bolivar, A. (2014). Las historias de vida del profesorado. Voces y contextos. Revista Mexicana de Investigación Educativa, 62(19), 711-734.

Boud, D., Cohen, R. y Walker, D. (eds.) (2011). El aprendizaje a partir de la experiencia. Interpretar lo vital y cotidiano como fuente de conocimiento. Madrid: Narcea.

Bruner, J. (1999). La educación, puerta de la cultura. Madrid: Visor.

Camas, V. (2001). Olvido y vigencia de El Campesino polaco en Europay América. EMPIRIA. Revista de Metodología de Ciencias Sociales, 4. Recuperado de http://e-spacio.uned.es/fez/eserv/bibliuned:Empiria-200194F0D29B-9E9F-E049-DD3E-6BFB62F4A095/Documento.pdf

Connelly, M. y Clandinin, J. (1995). Relatos de experiencia e investigación educativa. En J. Larrosa et al. (comps.), Déjame que te cuente. Ensayos sobre narrativa y educación (pp. 11-59). Barcelona: Laertes/ Psicopedagogía. 
Contreras. J. y Pérez, N. (2010). La experiencia y la investigación educativa. En J. Contreras y N. Pérez (comps.), Investigar la experiencia educativa (pp. 21-86). Madrid: Morata.

Fernández, M. (2012). Aportes de la aproximación biográfico-narrativa al desarrollo de la formación y la investigación sobre formación docente. Revista de Educación, 4, 11-36. Mar del Plata, Argentina: Facultad de Humanidades, Universidad Nacional de Mar del Plata.

Flick, U. (2004). Introducción a la investigación cualitativa. Madrid: Morata.

Goodson, I. (ed.) (2004). Historias de vida del profesorado. Barcelona: Octaedro-eub.

Huchim, D. y Reyes, R. (2013). La investigación biográfica- narrativa, una alternativa para el estudio de los docentes. Actualidades Investigativas en Educación, 13(3). https://doi.org/10.15517/aie.v13i3.12026

Larrosa, J. et al. (comps.). (1995). Déjame que te cuente. Ensayos sobre narrativa y educación. Barcelona: Laertes/Psicopedagogía.

, F. y Giménez, V. (2009). Historia de vida y métodos biográficos. En I de Gialdino (coord.), Estrategias de investigación cualitativa (pp. 175-212). Barcelona: Gedisa.

Moriña, A. (2017). Investigar con historias de vida. Metodología biográficonarrativa. Madrid: Narcea.

Pons, L. y Hernández, N. (coords.). (2013). Narrativas sobre la escuela. Voces, significados y experiencias de vida en instituciones educativas chiapanecas. México: Universidad Autónoma de Chiapas.

Pujadas, J. (1992). El método biográfico: el uso de las historias de vida en ciencias sociales. España: Centro de Investigaciones Sociológicas.

Taylor, S. y Bogdan, R. (1987). Introducción a los métodos cualitativos de investigación. Barcelona: Paidós Básica.

Reséndiz, R. (2015). Biografía: proceso y nudos teóricos metodológicos. En M. Tarrés (coord.), Observar, escuchar y comprender sobre la tradición cualitativa en la investigación social (pp.127-158) México: Flacso y El Colegio de México, A.C.

Ricoeur, P. (2013a). Tiempo y Narración I. Configuración del tiempo en el relato histórico. México: Siglo XXI.

Ricoeur, P. (2013b). La memoria, la historia, el olvido. México: Siglo XXI. Sanz, A. (2005). El método biográfico en investigación social: potencialidades y limitaciones de las fuentes orales y los documentos personales. Asclepio, 47(1). Recuperado de http://www.eduneg.net/ generaciondeteoria/files/SANZ-2005-El-metodo-biografico-en-lainvest-social.pdf 
Rosario Landín Miranda, Sandra Ivonne Sánchez Trejo

Zambrano, M. (2006). Filosofía y poesía. México: Fondo de Cultura Económica.

Zemelman, H. (2002). Necesidad de conciencia. Un modo de construir conocimiento. México D.F.: El Colegio de México, A. C., Anthropos. https://doi.org/10.2307/j.ctv6jmxzf 